"The final publication is available at Springer via http://link.springer.com/article/10.1007/s10683-014-93979/fulltext.html [DOI: 10.1007/s10683-014-9397-9]." 


\title{
Self-selection into laboratory experiments: Pro-social motives vs. monetary incentives
}

\author{
Johannes Abeler ${ }^{*}$ and Daniele Nosenzo**
}

21 December 2013

\begin{abstract}
:
Laboratory experiments have become a wide-spread tool in economic research. Yet, there is still doubt about how well the results from lab experiments generalize to other settings. In this paper, we investigate the self-selection process of potential subjects into the subject pool. We alter the recruitment email sent to first-year students, either mentioning the monetary reward associated with participation in experiments; or appealing to the importance of helping research; or both. We find that the sign-up rate drops by two-thirds if we do not mention monetary rewards. Appealing to subjects' willingness to help research has no effect on sign-up. We then invite the so-recruited subjects to the laboratory to measure their pro-social and approval motivations using incentivized experiments. We do not find any differences between the groups, suggesting that neither adding an appeal to help research, nor mentioning monetary incentives affects the level of social preferences and approval seeking of experimental subjects.
\end{abstract}

Keywords: Methodology; Selection bias; Laboratory experiment; Field experiment; Otherregarding behavior; Social preferences; Social Approval; Experimenter Demand.

JEL: C90, D03

Acknowledgments: We thank Jacob K. Goeree, two anonymous referees, Steffen Altmann, Stephen V. Burks, Simon Gächter, David Gill, David Huffman, John List, Nikos Nikiforakis, Collin Raymond, and Chris Starmer for helpful comments. We gratefully acknowledge support from the Leverhulme Trust (ECF/2010/0636).

*University of Oxford, IZA, and CESifo. e-mail: johannes.abeler@economics.ox.ac.uk

** University of Nottingham, e-mail: daniele.nosenzo@nottingham.ac.uk 


\section{Introduction}

Laboratory experiments have become a wide-spread tool in economic research. They have delivered many new insights about what preferences people hold, how people maximize their preferences, and how people interact. Yet, there is still doubt about how well the behavior in lab experiments generalizes to non-laboratory setups, and how well the behavior of lab subjects generalizes to other groups of decision makers. In this paper, we focus on the second issue and investigate what drives the self-selection process into economics lab experiments.

Research on self-selection into psychology experiments (e.g., Rosenthal and Rosnow, $1969 ; 1975)$ has often concluded that subjects participate for pro-social reasons, wanting to help the researchers, or because of their need for social approval. This has led some economists to conjecture that lab experiments exaggerate the extent of social preferences: if subjects come to the lab to help researchers, one would expect that these subjects are more pro-social (Levitt and List, 2007). Economics lab experiments, however, differ from most psychology experiments in that participants are paid according to their decisions. It could thus be that the self-selection process into economics lab experiments differs and is at least partly based on the expected monetary payment. In fact, one may be concerned that subjects in economics lab experiments are less pro-social than the overall student population. This concern may be further compounded by the over-representation of economics students in the typical experimental subject pool, which, it has been argued, are less pro-social because of indoctrination or self-selection (Frank et al., 1993; Frey and Meier, 2003; Bauman and Rose, 2011).

To investigate the selection process into economics experiments, we conducted a field experiment in which we altered the recruitment message sent to first-year university students inviting them to join the experimental subject pool. ${ }^{1}$ Subjects could be in one of three treatments: in the Money\&Appeal treatment the recruitment email stated that subjects can earn money and contained an appeal for their help. To check whether volunteering for lab experiments is about earning money, we dropped any mentioning of money from the email in the second treatment and only focused on the appeal for help (AppealOnly treatment). To check whether volunteering is about pro-social motivation and need for approval, we changed the recruitment email such that participants were only informed about the monetary payment

\footnotetext{
Recruitment into lab experiments is usually a two-step process: first, students sign up for the subject pool. This only documents their interest in receiving invitations for experiments. Invitations to actual experiments, including exact time slots, are then sent to sub-groups of the subject pool and recipients of these invitations can decide whether to participate or not.
} 
(MoneyOnly treatment). We compare the sign-up rates in the three treatment groups to understand the self-selection mechanism into lab experiments. To inform our treatment comparisons, we use a simple model of self-selection in which subjects sign up to experiments because of monetary and/or pro-social or approval-need motives. We show that the comparison between Money\&Appeal and AppealOnly can be used to gauge the importance of monetary reasons for participating in experiments; the comparison between Money\&Appeal and MoneyOnly measures the importance of pro-social reasons.

We find that the sign-up rate drops by about two-thirds if we do not mention monetary rewards. Appealing to subjects' willingness to help research has no effect on sign-up. In the Money\&Appeal and MoneyOnly treatments, 13.8 and 14.6 percent of contacted students sign up respectively. These two rates are not statistically significantly different from each other. In the AppealOnly treatment, only 5.0 percent sign up, significantly less than in either of the other treatments. These results suggest that the expected monetary payments are the main driver of selection into economics lab experiments.

While we do not find an effect of the appeal on net sign-up rates, it could still be that including the appeal into the recruitment email attracts different types of subjects in terms of their pro-social motivation. For example, it could be that the appeal decreases subjects' beliefs about the amount they may be paid for participating in the experiments, reducing sign-up and offsetting a possible positive direct effect of the appeal. We thus invited the so-recruited subjects for a lab experiment to verify whether the null effect of the appeal on net sign-up also translates into a similar null effect on pro-social and approval motivations of the selected subjects. In a series of incentivized experiments, we measured subjects' social values, cooperativeness, and sensitivity to experimenter demand, using a series of commonly used tasks in the literature on pro-social and approval motives. If one is concerned about the external validity of lab experiments, our test of experimenter demand should be especially of interest: subjects who attend lab experiments to help the researchers will also alter their behavior during the experiment in light of what they expect helps the researchers most.

We do not find any significant differences in the distribution of pro-social and approval motives across treatments. Adding an appeal to help research does not only leave the sign-up rate unchanged, it also does not affect the level of social preferences and approval seeking in the so-recruited population. This result strengthens the findings from the field experiment that pro-social motivations play only a minor role in the process of selection into economics experiments. 
Our results suggest that it is unlikely that the self-selection of participants into experiments leads to an over-estimation of social preferences. Our paper also addresses a second concern that has not been as prominent in the literature: Assume that selection into lab experiments is indeed driven by pro-social motives. Then self-selected participants should have higher measures of social preferences. If studies find no such difference between subjects and non-subjects (as it is the case, for example, for Cleave et al., 2013 and Falk et al., 2013), then the conclusion must be that lab measurements of social preferences are poorly correlated with true pro-social motives. Viewed this way, if selection is driven by pro-social motives, we face a Catch-22 and the use of lab experiments to gauge the importance of social preferences is never a good idea: either they exaggerate the prevalence of social preferences (because of the selection) or they are not able to predict pro-social behavior outside the lab. The jury is still out on how well lab-experimental measures of social preferences predict behavior outside the lab (compare, for example, Rustagi et al., 2010 with Stoop et al., 2012; see Camerer, 2011 and Coppock and Green, 2013 for overviews); our results, however, suggest that a simple story of self-selection via social preferences cannot be used to argue against these labexperimental measures.

We contribute to the fast-growing literature that examines the generalizability of lab experimental results, part of which focuses on the effect of selection. Most of these studies take the selection process as given and examine whether the selected sample differs from the total population (e.g., Cleave et al., 2013; Falk et al., 2013; Slonim et al., 2013), from other non-selected samples (e.g., Eckel and Grossman, 2000; Gaudecker et al., 2012; Anderson et al. 2013), or from other selected samples (e.g., Burks et al., 2009; Belot et al., 2010; Anderson et al. 2013). In contrast, our paper tries to influence the selection process directly to understand what brings subjects to the lab. ${ }^{2}$ The paper most closely related to ours is Krawczyk (2011), who also changes the invitation to lab experiments and observes, like we do, that subjects enter the pool more often when monetary rewards are prominent. ${ }^{3}$ However,

\footnotetext{
- Other studies have investigated how differences in recruitment procedures may affect participation rates and subsequent behavior. Harrison et al. (2009), for instance, study how information about guaranteed show-up fee for participating in experiments affects selection on risk attitudes. There has also been research on the effects of various forms of recruitment outside economics. Tomporowski et al. (1993), for example, compare the performance on laboratory tests of attention and memory of subjects who received monetary incentives, coursecredit incentives, or for whom participation was a course requirement. Tishler and Bartholomae (2002) review the literature on the role of financial incentives in healthy volunteers' decision to participate in clinical trials. ${ }^{3}$ Relatedly, Cubitt et al. (2011) report that monetary incentives increase rates of survey participation. They also find that the different participation incentives do not affect responses in the survey. Also related is the study by Guillén and Veszteg (2012) who find that the decision to repeatedly participate in laboratory experiments is positively related to subjects' financial performance in previous experiments.
} 
our study extends Krawczyk's design in several important dimensions: i) Since Krawczyk compares only two treatments (emphasizing either the monetary or non-monetary rewards of participation), he can only state that the monetary motive is more important than nonmonetary motivations. With our three treatments, we can separately identify the effect of monetary and non-monetary motives. ii) The AppealOnly and MoneyOnly treatments suppress all information about monetary or non-monetary rewards respectively, while Krawczyk only changes the emphasis and always mentions money. We also made sure that no information about monetary payments for experiments at our university was available on the web while we sent out the recruitment emails. This strengthens our finding that even under our treatment variation subjects' behavior does not differ across treatments. iii) Finally, and most importantly, we run a whole battery of incentivized preference elicitation experiments with our differently-recruited subjects to test different nuances of pro-social and approval seeking behavior. Krawczyk focuses instead on subjects' willingness to participate in an unpaid survey and an un-incentivized altruism measure derived from the survey as outcome variables.

The paper is structured as follows. In the next section we present the design and results of our field experiment. We also present a very simple model of self-selection into lab experiments to provide for a clearer interpretation of design and results. Section 3 reports the design and results of the lab experiment. Section 4 concludes.

\section{Field Experiment}

\subsection{Design}

In October 2010 we sent an email to 5725 first-year undergraduate students at the University of Nottingham inviting them to volunteer for research studies involving laboratory and internet experiments conducted at the School of Economics Centre for Decision Research and Experimental Economics (CeDEx). Students had only recently arrived at the university and were thus not accustomed to economics lab experiments. Students were randomly assigned to one of three treatments, which differed in the content of the recruitment email message (reproduced in Online Appendix A).

In all treatments the email contained a brief description of what an economics experiment is, and included a link to a website where students could complete the registration. The treatments differed in whether or not the email contained several sentences 
1) informing students that participation in experiments is usually rewarded with a cash payment; and 2) appealing to students' willingness to help scientific research.

This information is typically provided in invitation letters used to recruit students to volunteer for experimental research, and this was also the case for invitations sent in previous years at Nottingham. In our Money\&Appeal treatment the email message contained both the information about cash payments (e.g., "You will typically receive some reward (usually cash) in return for your participation") and the appeal for students to volunteer(e.g., "Your participation is crucial to the success of our research, and we will highly appreciate your contribution and be really grateful for your collaboration"). In the MoneyOnly treatment we used the same email as in Money\&Appeal but deleted all sentences emphasizing the value of participation. Finally, in the AppealOnly treatment students received the same email as in Money\&Appeal but without references to the existence of financial incentives. ${ }^{4}$

Students were randomly assigned to treatments depending on the last digit of their student ID number. With this procedure we assigned 1722 students to Money\&Appeal, 1734 students to MoneyOnly and 2269 students to AppealOnly. ${ }^{5}$ The emails were sent out on October $7^{\text {th }} 2010$. We focus on responses to the invitation emails between October $7^{\text {th }}$ and October $24^{\text {th }}$. On October $24^{\text {th }}$, in fact, all subjects who had by then agreed to volunteer were sent an email inviting them to a laboratory experiment, described in detail in Section 3.

As highlighted by Levitt and List (2007) and List (2007), a long tradition of research in social psychology has focused on the characteristics of subjects volunteering for psychological experiments. This research suggests that the decision to participate in an experiment may be driven by pro-social motives, such as altruism or cooperativeness towards the experimenter, and by a desire to seek social approval. ${ }^{6}$ The recruitment email used in Money\&Appeal (and AppealOnly) appealed to these motives. Students were told that their participation was of great value for academic research, and that researchers would highly appreciate students' contribution and be grateful for their collaboration. The appeal plays on

\footnotetext{
Students completed the registration via a website (http://www.nottingham.ac.uk/ lezorsee/orsee/public/) hosting the web-based online recruitment system ORSEE (Greiner, 2004). The website also contains additional details about the Research Centre, and a statement about our privacy policy and a description of the rules and practices that participants must agree to abide by. Students can also use the website to browse through a list of frequently asked questions. During the whole period of the experiment (October $7^{\text {th }} 2010$ to November $15^{\text {th }}$ 2010) we temporarily disabled any feature of the website (and of any University webpage linking to it) that could void our treatment manipulations (e.g., we temporarily removed the FAQ: "Do you pay me for participating in experiments? How much?").

Since each student ID number can end with 1 of 10 possible digits and there are only 3 treatments, we had to assign 4 possible end-digits to one treatment.

For a comprehensive review of this literature see Rosenthal and Rosnow (1975).
} 
students' pro-social and approval motives in two ways. First, the explicit reference to the researchers as beneficiaries of the volunteering activity aims to reduce the psychological distance between the donor (the subject) and the donee (the researchers), and thus trigger a stronger empathic response from the subject. Previous research has shown that being able to identify the beneficiary of a pro-social act increases pro-social behavior (the "identifiable victim effect”; see, e.g., Jenni and Loewenstein, 1997; Small and Loewenstein, 2003). More generally, there is evidence that reducing social distance between the interacting parties increases pro-social behavior (Hoffman et al., 1996; Bohnet and Frey, 1999;

Charness and Gneezy, 2008). Moreover, the emails highlight the potential rewards in terms of approval and appreciation of participating, and thus make these motives more salient.

On the other hand, the email received by students in the MoneyOnly treatment did not contain any appeal to volunteer. We can thus assess the strength of the pro-social and approval-need motives for volunteering by comparing the recruitment response rates in Money\&Appeal and MoneyOnly: if pro-social and approval need motives are important determinants of the decision to volunteer, Money\&Appeal should yield a higher response rate than MoneyOnly.

As already noted by Kagel et al. (1979), an important difference between psychology and economics experiments is that in the latter participants typically receive nontrivial financial incentives for participation. The decision to volunteer for economics experiments could thus be predominantly driven by the prospects of financial reward, and this may reduce the role of the pro-social and approval need motives relative to psychological experiments. In fact, the use of financial incentives in economics experiments may lead to an overrepresentation of subjects who are mainly interested in maximizing their own material gain.

To examine the role of financial incentives in the decision to volunteer for experiments we compare recruitment response rates in Money\&Appeal and AppealOnly. In both treatments students received the same appeal to volunteer for experimental research. Students in Money\&Appeal were also informed about the existence of financial incentives for participating in experiments, whereas students in AppealOnly did not receive this information. Thus, if the decision to volunteer for experimental research is driven by financial incentives, Money\&Appeal should yield a higher response rate than AppealOnly. 


\subsection{Model}

To further formalize our research strategy, we suggest the following stylized model of selfselection, which captures the intuition that subjects might participate because of monetary incentives and/or because of pro-social or approval-need motives.

In the model, subjects decide whether to participate in lab experiments or not; we take the sign-up decision to the subject pool as a proxy for the willingness to participate. The utility of not participating is normalized to zero. The utility of participation is

$$
U=-c+a^{\prime}(a+1) m+8(b+1) s
$$

$c$ is the cost of participation, which includes the time spent at the lab, the expected cognitive effort to be expended, potential boredom, etc. We assume that this cost is heterogeneous in the population to allow for interior solutions. $m$ is the prior belief about the expected monetary payoff. The posterior belief (after the invitation emails) is $(a+1) m$. We assume that the two Money treatments (Money\&Appeal and MoneyOnly) increase the posterior by $a m$ while AppealOnly leaves the posterior at $m$. The field experimental data will inform us on the weight $a^{\prime}$ subjects place on monetary incentives for participation. If the sign-up rate in Money\&Appeal is higher than in AppealOnly, we would conclude that $a^{\prime}>0$. If the signup rate is the same across these two treatments, we would conclude that monetary payments do not play a big role for the decision to sign up (i.e., $a^{\prime}=0$ ).

As discussed earlier, subjects could also sign up for pro-social and approval-need motives. In our utility function, we capture this by the term $8(b+1) s$, where $s$ is the baseline strength of subjects' social preferences/approval need, i.e., the level of altruistic action that they are willing to engage in without appeal. The laboratory experiment described in Section 3 will allow us to measure $s$ for each subject. To preview part of our results, we will find that $s>O$ for many subjects, replicating the previous literature on social preferences. We assume that in MoneyOnly only the baseline level of $s$ is present, and that the two Appeal treatments increase this term to $(b+1) s$ for the reasons we discussed in the previous subsection. We will use the field and lab experimental data to estimate the weight 8 subjects place on the pro-social part of their utility function when they decide whether to participate in lab experiments. ${ }^{7}$ If the sign-up rate in Money\&Appeal is higher than in

\footnotetext{
There are several reasons why people may not act on their pro-social motivations in certain situations. For example, people may be altruistic towards others only if these are in their reference group. Chen and Li (2009), for instance, find that subjects are more altruistic when matched with an 'ingroup' member than with an
} 
MoneyOnly, we would conclude that $/ 3>0$; if they are the same, we would conclude that $/ 3=0$.

One could also imagine that subjects do not interpret our Appeal treatments as an appeal, but rather as mere information that lab experiments are useful for researchers. ${ }^{8} \mathrm{We}$ would, however, expect that most subjects already believed this to be the case before our emails (along a simple revealed preference argument: why would researchers conduct experiments if they were not useful for them?). If this is the case, our treatment manipulation would not affect subjects' baseline level of altruism, and we would need to assume that $b=0$ and the pro-social term of the utility function is $/ 3 \mathrm{~s}$ in all treatments. As a consequence, the two Money treatments would be identical. We can nevertheless use our design to draw conclusions about $/ 3$. If the Money treatments are able to elicit a higher sign-up rate than AppealOnly (i.e., $\alpha>0$ ), then we would expect a higher average level of $s$ in AppealOnly compared to the Money treatments: since the expected monetary payoff in AppealOnly is lower, only very altruistic subjects will sign up while also subjects with low s will sign up in the Money treatments. Note that this reasoning rests on the assumption that $/ 3>0$. If $/ 3=0$, then AppealOnly could lead to a lower sign-up rate, but the average level of s will be the same across all three treatments. We can thus use the lab experimental measures of social preferences to (indirectly) test whether $/ 3 \geq 0$, even if $b=0 .{ }^{9}$

\footnotetext{
'outgroup'. In the context of our study, students may perceive the researchers/experimenters as an 'outgroup' member and may therefore not act altruistically towards them. The laboratory experiment by Frank (1998) is consistent with this view as it shows that subjects do not seem to care about the experimenter's welfare. Heyman and Ariely (2004) propose that social relationships can be based on economic or social exchanges, where the former are regulated by monetary and market considerations while the latter rely on nonmonetary exchanges. The extent to which subjects are willing to act on their pro-social motivation may thus depend on whether they view laboratory experiments participation as an economic or social exchange.

We thank an anonymous referee for pointing this out.

- There may also be a potential composition effect between Money\&Appeal and MoneyOnly that we can investigate using the lab experiment. Assume that subjects do not know the level of $(a+1) \mathrm{m}$. After all, the emails only mentioned that there will be a payment but did not specify the level. Subjects may then try to infer $(a+1) \mathrm{m}$ from the invitation email. Subjects may conclude that $(a+1) \mathrm{m}$ is lower in Money\&Appeal than in MoneyOnly since the experimenters apparently believe they need to offer both a monetary incentive and an appeal to make subjects sign up (this idea is similar to Bénabou and Tirole, 2003). This could lead to different types of subjects selecting into the two Money treatments, even if the overall sign-up rate is the same. This channel relies on the assumption that subjects in Money\&Appeal believe that the experimenters believe that $/ 3 b>0$, which is not an unreasonable belief given the email we sent, but do not rely on the true values of $/ 3$ and $b$.
} 


\subsection{Results}

We focus mainly on the comparisons of Money\&Appeal to MoneyOnly and Money\&Appeal to AppealOnly as these comparisons involve only one treatment manipulation each. We summarize our main findings in the following results:

RESULT 1 - Including an appeal to subjects' pro-social and approval motives in the invitation email does not affect response behavior.

RESULT 2 - Not informing subjects of the existence of financial incentives for participating in experiments reduces the response rate significantly.

We document these treatment effects in Figures 1 and 2. Figure 1 shows the proportions of invited students who registered to our database of volunteers for experiments in the three treatments. Figure 2 shows how registration rates developed over time.

\section{FIGURE 1}

Volunteering for Economics Experiments*

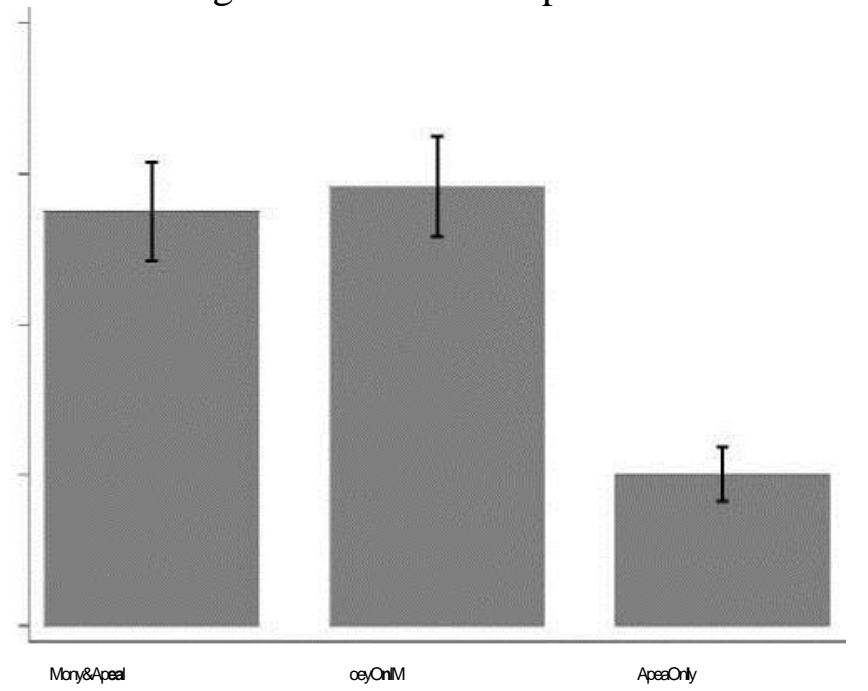

* Lines represent $95 \%$ confidence intervals. 
FIGURE 2

Volunteering for Economics Experiments over Time

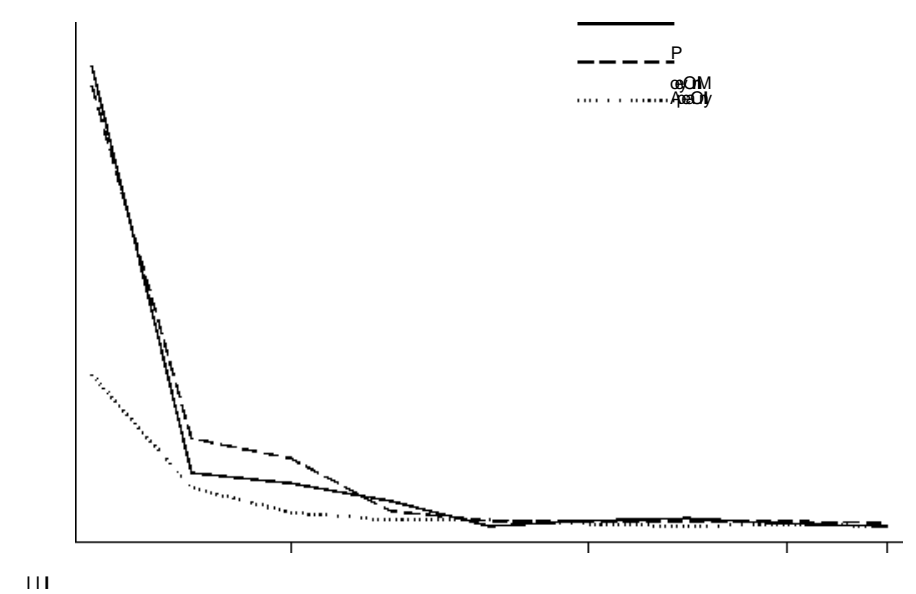

About 13.8 percent of the invited students completed the registration process in Money\&Appeal. The proportion of registered students in the MoneyOnly treatment is 14.6 percent, whereas only 5.0 percent of the students in AppealOnly registered to our database. As shown in Figure 2, these treatment differences are almost entirely attributable to differences in response behavior in the first forty-eight hours of the field experiment. Overall, we do not find a statistically significant difference in registration rates between MoneyOnly and Money\&Appeal $\left(\chi^{2}(1)=0.49, \mathrm{p}=0.486\right)$. The difference in registration rates between AppealOnly and Money\&Appeal is instead highly significant $\left(\chi^{2}(1)=93.21, \mathrm{p}<0.001\right) .{ }^{10}$ regstred gder We logit

Mange\& Appal

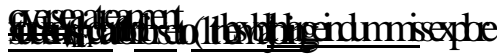 \\ frthr \\ filmminoresin




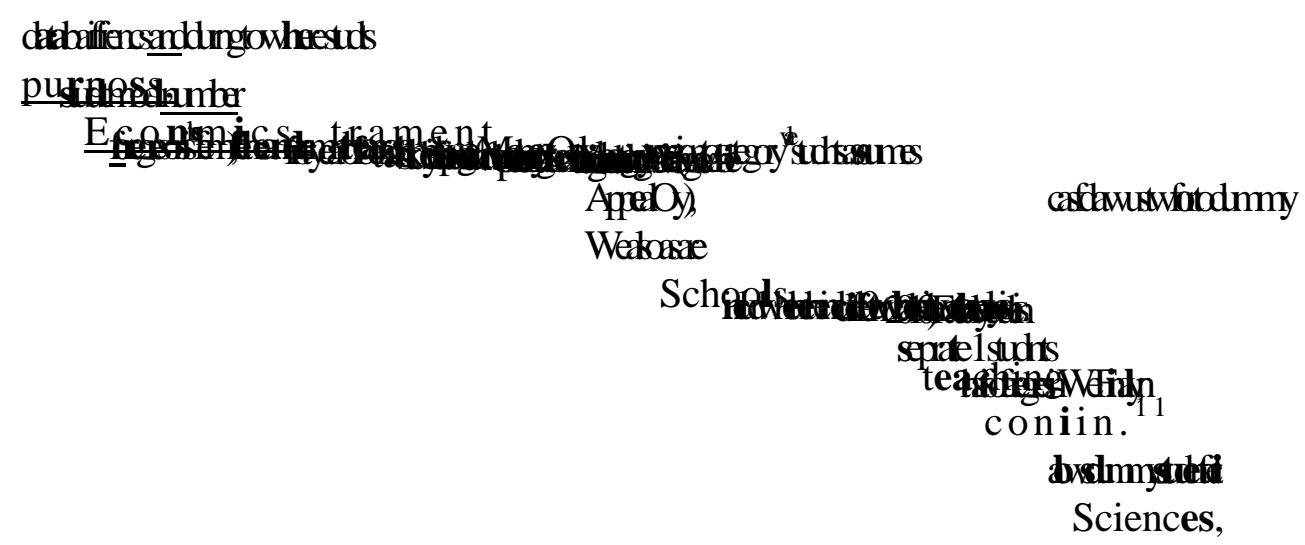

${ }_{10}$ The difference between MoneyOnly and AppealOnly is also highly significant $\left(\chi^{2}(1)=108.01, \mathrm{p}<0.001\right)$. "For each first-year undergraduate student we contacted via email we have information on gender, field of study and fee status (Home/EU or Overseas). 
(partially) based at campuses located at different distances from the main campus where the experiments are normally run (used as benchmark category). The regression results are reported in Table 1 (expressed as changes in the odds of registering to the database of volunteers for economics experiments).

TABLE 1

\begin{tabular}{|c|c|}
\hline MoneyOnly & $\begin{array}{l}1.08 \\
(.107)\end{array}$ \\
\hline AppealOnly & $\begin{array}{l}0 \mathbf{3 3}^{*} \\
(.039)\end{array}$ \\
\hline Female & $\begin{array}{l}1.04 \\
(.096)\end{array}$ \\
\hline Overseas & $\begin{array}{l}0.97 \\
(.141)\end{array}$ \\
\hline Arts & $\begin{array}{l}0.84 \\
(.113)\end{array}$ \\
\hline Social Sciences (excl. Economics) & $\begin{array}{l}1.03 \\
(.141)\end{array}$ \\
\hline Economics & $\begin{array}{l}3.37^{\circ} \\
(.594)\end{array}$ \\
\hline Engineering & $\begin{array}{l}0.78 \\
(.133)\end{array}$ \\
\hline Medicine & $\begin{array}{l}1.11 \\
(.281)\end{array}$ \\
\hline Campus \#2 (approx. 0.8 miles from main campus) & $\begin{array}{l}0.71 \\
(.149)\end{array}$ \\
\hline Campus \#3 (approx. 1.3 miles from main campus) & $\begin{array}{l}0.69^{* *} \\
(.112)\end{array}$ \\
\hline Campus \#4 (more than 10 miles from main campus) & $\begin{array}{l}0.44^{*} \\
(.119)\end{array}$ \\
\hline trk odds of registering to database & \\
\hline
\end{tabular}

$\mathrm{N}=5725$. The dependent variable takes value 1 if a subject registered to our database of volunteers between October $7^{\text {th }}$ and October $24^{\text {th }}$. Results are shown as factor changes in the odds of registering to the database. Robust standard errors in parentheses. Benchmark category: in Money\&Appeal, male, classified as Home/EU for fees purposes, studying a course in the Faculty of Science, whose School is based at the main campus. The category 'Overseas' includes 9 students who for fees purposes would be classified as 'Channel Island' students. The dummy Campus \#4 includes 317 students whose School is based at a campus at about 11 miles from the main campus, and 29 students from a campus located at approximately 16 miles from the main campus. Significance levels: * $10 \%$; ** 5\%;*** $1 \%$.

For subjects in the Money\&Appeal treatment the odds of volunteering for economics experiments are 0.17 , ceteris paribus. The regression shows that being in the AppealOnly treatment reduces the odds of volunteering by a factor of 0.33 . The effect is significant at the 1 percent level. Being in the MoneyOnly treatment has instead a positive effect on the odds 
of volunteering. However, the odds of registering only increase slightly (by a factor of $1.08)$ and the effect is statistically insignificant $(\mathrm{p}=0.434)$.

Among the controls, we find a strong positive effect of majoring in economics. This result compares with that by Krawczyk (2011), who also reports that economics students are significantly more likely to volunteer for experimental economics research. This effect could be explained by the fact that economics students may have greater interest and familiarity with experimental economics relative to students from other disciplines. ${ }^{12} \mathrm{We}$ also find that taking a course at Schools which are not located at the main campus (where the experiments are conducted) decreases the odds of volunteering. The size of this negative effects increases with the distance from the main campus. This seems reasonable, as students registered at Schools not located at the main campus may face higher costs of participation, e.g., transportation costs. This sensitivity to distance to the lab could also partly explain why economics students are more likely to register since the lab is located in the same building as the School of Economics (the campus dummies in Table 1 do not control for intra-campus distance and the familiarity with different parts of the campus).

Overall, these results suggest that financial incentives play an important role in the decision to volunteer for economics experiments. Removing any reference to financial incentives from the invitation email reduces the registration rate by about two-thirds. In contrast, removing the appeal to subjects' pro-social and approval motives has a small and insignificant effect on registrations, suggesting that these motives play a minor role in the decision to volunteer. ${ }^{13}$ In terms of the model presented in Section 2.2, we would thus conclude that $\mathrm{a}>0$ and $\beta=0$. This rests on the assumption that the Appeal emails were indeed interpreted as appeals, i.e., $\mathrm{b}>0$; we will address the case of $\mathrm{b}=0$ in the next section.

\footnotetext{
"Given the discussion in the literature about economics students behaving more selfishly than other students in experiments (e.g. Marwell and Ames, 1981; Frank et al., 1993; Frey and Meier, 2003), one may wonder whether economics students are also more sensitive to the email containing information about financial incentives. To test for this, we ran an additional regression where we interact the treatment dummies with the Economics dummy in Table 1 . We find that neither interaction term is significantly different from zero (all $\mathrm{p}>0.712$ ).

"One referee pointed out that the drop in registrations in AppealOnly may reflect a "social learning" effect: if subjects in AppealOnly had somehow become aware that economics experiments usually involve monetary incentives (e.g., by word-of-mouth from students from previous years), they may have decided to decline the invitation to sign up for the unpaid experiments as they waited to receive an invitation for the paid studies. While we think that this is not very likely (the recruitment took place at the very beginning of the academic year, when first-year students had only limited opportunities to engage with students from previous years), we view such a mechanism in line with our conclusion that selection into experiments is mostly driven by the desire to earn money.
} 


\section{Laboratory Experiment}

The main purpose of the lab experiment was to obtain laboratory measurements of pro-social and approval need motives for the volunteers recruited through our field experiment (we also collected a range of measurements on subjects' risk preferences and cognitive skills). In terms of our model, we can thus estimate the level of s for each subject. Moreover, while the results of our field experiment show that appealing to subjects' pro-social motivations has an insignificant effect on the net sign-up rate between Money\&Appeal and MoneyOnly, it is possible that the differences in recruitment messages may have had an impact on the composition of the subject pool, i.e. on the types of subjects who sign up. We can use the lab experiment to ascertain whether this is the case. Finally, as discussed above, we can use the lab experiment to test whether subjects sign up for pro-social reasons (i.e., whether $\beta>0$ in our model) even if the appeal manipulation was unsuccessful (i.e. if $b=0$ ).

\subsection{Design}

Subjects were invited to participate on October $24^{\text {th }}$, and the experiment took place between October $29^{\text {th }}$ and November $9^{\text {th }}$. All students received the same invitation email (reproduced in Online Appendix B), regardless of the treatment they were assigned to in the field experiment. 67 subjects recruited via Money\&Appeal and 78 recruited via MoneyOnly participated in the lab experiment. Since only few subjects reacted to the AppealOnly recruitment email, we were only able to sign up 29 AppealOnly subjects for the lab experiment.

Each session consisted of 6 parts. Subjects were informed at the beginning of the experiment of the existence of the 6 different parts, but detailed instructions about each part were only given upon completion of the previous one (all instructions are reproduced in Online Appendix B). Any information about earnings from any part of the experiment was only given at the end of part 6 . Subjects were paid according to the sum of the earnings they made in each part of the experiment. Earnings were computed in points during the experiment and converted into British Pounds at a rate of $£ 0.10$ per point. Table 2 shows the timeline of a session. 
TABLE 2

Timeline of the lab experiment

\begin{tabular}{l|cc}
\hline \hline & Task(s) & Measurement \\
\hline & & \\
Part 2 & Public Goods Game & Cooperativeness \\
Part 3 & Lottery choice & Risk attitudes \\
Part 4 & SDS-17 Scale; & \\
Part 5 & Gudjonsson's Compliance Scale & Social approval need \\
Part 6 & Tsutsui and Zizzo's & Social approval need \\
& experimenter demand test & \\
Cognitive Reflection Test; & Cognitive skills \\
\hline \hline
\end{tabular}

In the first two parts of the experiment we collected measurements of subjects' prosocial motivation using two commonly used tasks in the social preference literature: the Decomposed Game Technique (part 1) and a Public Goods Game (part 2). The Decomposed Game Technique elicits subjects' 'social value orientation', i.e. the goal that individuals pursue in social interactions involving trade-offs between own and others' material wellbeing (see, e.g., Liebrand, 1984; Offerman et al., 1996; Park, 2000; Brosig, 2002; Levati et al., 2011). Subjects were randomly paired with another participant and made a series of 24 choices between two allocations, each specifying different amounts of money for the decision-maker and the opponent. Subjects' payoffs in a choice situation depended on the choices they and their opponent made in that situation. The total earnings from part 1 were determined by the sum of the earnings made in the 24 choice situations (taken from Park, 2000 and reproduced in Online Appendix C). Subjects were matched with a different person after part 1 .

In part 2, we measured subjects' cooperativeness using the one-shot Public Goods Game introduced by Fischbacher et al. (2001). Subjects were matched in groups of 4 and endowed with 20 tokens each, which they could keep or contribute to a public good. Earnings were computed as:

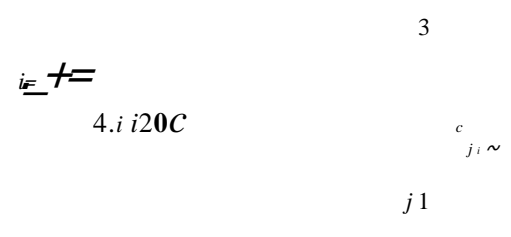

Following Fischbacher et al. (2001) we elicited two types of contribution decisions. First, subjects submitted an unconditional contribution $c_{i}$ to the public good. Subjects then had to specific a contribution $c_{i}$ for each of the possible 21 (rounded) average contributions 
(from 0 to 20) of the three other players in their group. The two types of decisions were elicited in an incentive compatible way: at the end of the experiment, a random mechanism selected for each group one member for whom the conditional contribution was relevant and three members for whom the unconditional contributions were relevant. The (rounded) average of the three unconditional contributions determined which of the 21 selected conditional contribution decisions was relevant. The sum of these four contributions was the total amount contributed by the group to the public good.

In part 3 of the experiment we elicited subjects' risk attitudes using the lottery choice task also used by Cleave et al. (2013). Subjects were presented with the six 50-50 lotteries shown in Table 3, and had to choose one to be played out at the end of the experiment. Moving from Lottery 1 to 6 , the risk associated with each lottery decreases, and the expected payoffs of lotteries 2 to 6 also decrease. More risk-averse subjects should thus choose lotteries further down the table.

TABLE 3

\begin{tabular}{|c|c|c|c|c|}
\hline \multicolumn{5}{|c|}{ Part 3 - Lottery Task ${ }^{*}$} \\
\hline & $\begin{array}{c}\text { Outcome A } \\
\text { (Probability 50\%) }\end{array}$ & $\begin{array}{c}\text { Outcome B } \\
\text { (Probability 50\%) }\end{array}$ & $\begin{array}{l}\text { Expected } \\
\text { Value }\end{array}$ & $\begin{array}{l}\text { Standard } \\
\text { Deviation }\end{array}$ \\
\hline Lottery 1 & 60 & 0 & 30 & 30 \\
\hline Lottery 2 & 54 & 6 & 30 & 24 \\
\hline Lottery 3 & 46 & 10 & 28 & 18 \\
\hline Lottery 4 & 38 & 14 & 26 & 12 \\
\hline Lottery 5 & 30 & 18 & 24 & 6 \\
\hline Lottery 6 & 22 & 22 & 22 & 0 \\
\hline
\end{tabular}

* Subjects were not shown the columns reporting expected values and standard deviations.

In parts 4 and 5 we elicited subjects' social approval need. In part 4 subjects completed two unincentivized questionnaires, the Social Desirability Scale (SDS-17; Stöber, 2001), and Gudjonsson's Compliance Scale (GCS; Gudjonsson, 1989), both reproduced in Online Appendix D. The SDS-17 is (somewhat confusingly) a 16-item scale measuring the extent to which subjects over-report socially desirable behaviors and attitudes (e.g., "I always eat a healthy diet") and under-report social undesirable ones (e.g., "I occasionally speak badly of others behind their back"). The GCS is a 20-item scale that measures subjects' propensity to comply with requests made by others, especially if in a position of authority. Subjects 
indicate their agreement with statements such as "I find it very difficult to tell people when I disagree with them". Answers to both questionnaires were recorded using a true/false scale. ${ }^{14}$ In part 5 we measured subjects' approval need using the task proposed by Tsutsui and Zizzo (forthcoming) to assess subjects' sensitivity to experimenter demand (Zizzo, 2010). Subjects were presented with six pairs of 50-50 lotteries (shown in Table 4), and for each pair they had to select one lottery, A or B. Lottery A and B were identical in the first row. In subsequent rows, A became more attractive and B less attractive. At the end of the experiment, a random mechanism selected one pair for each subject and played the lottery from the pair that was chosen by the subject. Subjects were 'nudged' to select the (weakly) dominated lottery B: a smiley face was placed in the column corresponding to lottery B, and a sentence in the instructions read "It would be nice if at least some of you were to choose B at least some of the time". We take the number of times a subject selects lottery B over lottery A as a measure of their sensitivity to experimenter demand.

TABLE 4

\begin{tabular}{l|cc}
\multicolumn{3}{c}{ Part 5 - Tsutsui and Zizzo's Task } \\
\hline \hline & $\begin{array}{c}\text { Lottery A } \\
(50 \%-50 \%)\end{array}$ & $\begin{array}{c}\text { Lottery B } \\
(50 \%-50 \%)\end{array}$ \\
\hline Pair 1 & $10-30$ & $10-30$ \\
Pair 2 & $11-31$ & $9-29$ \\
Pair 3 & $12-32$ & $8-28$ \\
Pair 4 & $13-33$ & $7-27$ \\
Pair 5 & $14-34$ & $6-26$ \\
Pair 6 & $15-35$ & $5-25$ \\
\hline \hline
\end{tabular}

In part 6 of the experiment, subjects completed two cognitive skills tests: the 3 -question Cognitive Reflection Test (CRT; Frederick, 2005) and the 5-question financial literacy test developed for the English Longitudinal Study of Ageing (e.g., Banks and Oldfield, 2007), both reproduced in Online Appendix E. For each correct answer subjects received $£ 0.20$.

Upon completion of part 6 , subjects received feedback about the earnings accumulated through the 6 parts of the experiment. A short questionnaire followed, collecting basic sociodemographic information, risk attitudes (using the SOEP general risk question, e.g., Dohmen et al., 2011), and trust attitudes (using the General Social Survey trust question, e.g., Glaeser et al., 2000). Once subjects had finished the questionnaire they were paid their earnings and

\footnotetext{
"To check whether the order in which subjects took the questionnaires affected responses, we had half of the subjects in a session complete the SDS-17 scale first, while the other half completed the GCS scale first. We do not find significant differences between the two orderings ( $p>0.173$ using Wilcoxon rank-sum tests), and we thus pool the data from the two sub-groups.
} 
left the laboratory. Sessions lasted about 90 minutes, and average earnings (inclusive of a $£ 1.50$ show-up fee) were $£ 12.50$ (s.d. $£ 2.40$ ). The experiment was programmed in zTree (Fischbacher, 2007).

\subsection{Results}

We summarize our main findings in the following result:

RESULT 3 - We do not find any significant treatment differences in subjects' pro-social and approval seeking behavior between Money\&Appeal and MoneyOnly, or between Money\&Appeal and AppealOnly.

Starting with the Decomposed Game, we follow a standard technique developed by social psychologists (see, e.g., Liebrand, 1984 and Brosig, 2002) to classify subjects depending on the predominant patterns of their choices in the game. Subjects are classified as: i) 'aggressive', if they (mainly) make choices that minimize the opponent's payoff; ii) 'competitive', if they maximize the difference between their payoff and the opponent's payoff; iii) 'individualistic', if they maximize their own payoff; iv) 'cooperative', if they maximize aggregate payoffs; and v) 'altruistic', if they maximize their opponent's payoff. ${ }^{15}$ Figure 3 shows the distribution of types across treatments. The distributions are not significantly different (Fisher's exact tests; Money\&Appeal vs. MoneyOnly: $p=0.544$; Money\&Appeal vs. AppealOnly: $\mathrm{p}=0.937)$.

\section{FIGURE 3}

Social Value Orientations in the Decomposed Game
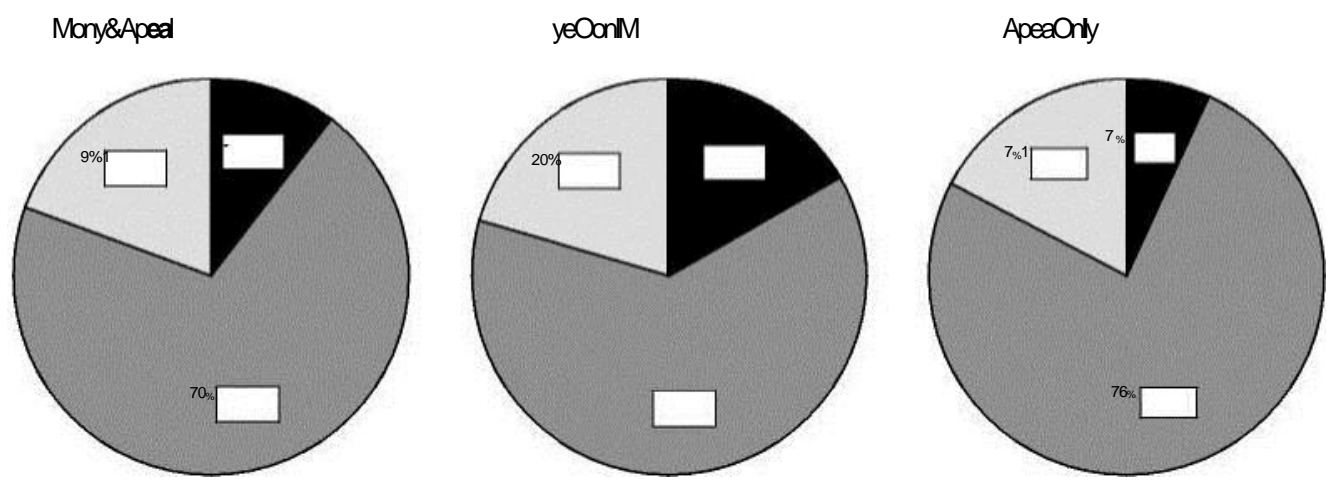

complie

noduesic

\footnotetext{
is No subjects could be classified as 'aggressive' or 'altruistic' in our experiment.
} 
Turning to the public goods game, we follow Fischbacher et al. (2001) and use the conditional contributions to classify subjects into four different types: 'free riders', 'conditional cooperators', 'triangle contributors' and 'others'. Figure 4 shows that the distribution of types is extremely similar across treatments, and we cannot reject the null hypothesis of equal distribution of types (Fisher's exact tests; Money\&Appeal vs.

MoneyOnly: $\mathrm{p}=1.000$; Money\&Appeal vs. AppealOnly: $\mathrm{p}=0.887) .{ }^{16}$

\section{FIGURE 4}

Cooperativeness in the Public Goods Game
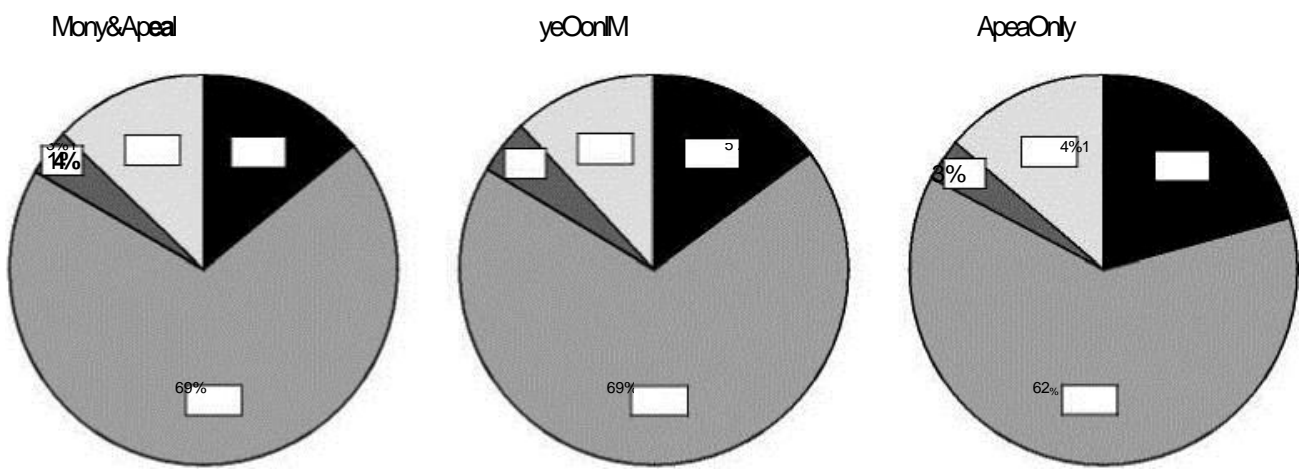

We now turn to our measures of social approval need. Table 5 shows the descriptive statistics of the SDS-17 and GCS scales as well as the number of times subjects selected the weakly-dominated lottery in the Tsutsui and Zizzo's experimenter demand task. In all cases, higher values are indicative of higher need of social approval.

${ }_{16}$ We also find no significant differences in subjects' unconditional contributions (Mann-Whitney tests; Money\&Appeal vs. MoneyOnly: $p=0.989$; Money\&Appeal vs. AppealOnly: $p=0.383$ ) or subjects' selfreported trust attitudes as measured by the GSS trust question included in the post-experimental questionnaire (Fisher's exact tests; Money\&Appeal vs. MoneyOnly: $p=0.407$; Money\&Appeal vs. AppealOnly: $p=0.119$ ). 
TABLE 5

\begin{tabular}{|c|c|c|c|c|}
\hline & & Social Approval & eed & \\
\hline & & Money\&Appeal & MoneyOnly & AppealOnly \\
\hline & Mean & 8.18 & 8.5 & 8.41 \\
\hline SDS-17 & Std. Dev. & 3.18 & 3.14 & 3.37 \\
\hline & Median & 9 & 9 & 9 \\
\hline & Mean & 8.97 & 8.65 & 9.90 \\
\hline GCS & Std. Dev. & 3.01 & 3.44 & 3.88 \\
\hline & Median & 9 & 8.5 & 10 \\
\hline & Mean & 1 & 1.28 & 1.28 \\
\hline Tsutsui \& & Std. Dev. & 0.92 & 1.02 & 1.29 \\
\hline Zizzo's task & Median & 1 & 1 & 1 \\
\hline & Min-Max & $0-4$ & $0-4$ & $0-6$ \\
\hline
\end{tabular}

We do not find marked differences across treatments in any of our measurements, and we cannot reject the hypothesis that the samples have been drawn from the same distribution using Mann-Whitney tests in the SDS-17 (Money\&Appeal vs. MoneyOnly: $\mathrm{p}=0.588$; Money\&Appeal vs. AppealOnly: $\mathrm{p}=0.686$ ) or GCS (Money\&Appeal vs. MoneyOnly: $\mathrm{p}=$ 0.465; Money\&Appeal vs. AppealOnly: $p=0.217$ ). We also do not find a significant difference in the Tsutsui and Zizzo's task between Money\&Appeal and AppealOnly ( $\mathrm{p}=$ 0.368 ), but we do find a marginally significant difference between Money\&Appeal and MoneyOnly $(\mathrm{p}=0.083)$. However, the point estimate goes in the opposite direction of what one would expect: appealing to the social approval needs (as in Money\&Appeal) selects subjects who are a little less prone to experimenter demand.

While the main aim of our lab experiment was to collect measurements of pro-social and approval motives, we also measured subjects' risk preferences (part 3) and cognitive skills (part 6). We again do not find significant treatment differences in these measures. ${ }^{17}$

Overall, we do not find evidence of systematic differences in our lab measurements of pro-social motivation and social approval need across volunteers attracted by different recruitment messages. This reinforces our result from the field experiment that pro-social and approval motives play a small role in the decision to take part in economics experiments.

In terms of the model presented in Section 2.2, we conclude from the lab experiment that $s>0$ for most subjects. Moreover, the lab experiment also shows that the distribution of pro-social and approval motives is not significantly different across the two Money

\footnotetext{
${ }_{17}$ Money\&Appeal vs. MoneyOnly: lottery task: $\mathrm{p}=0.574$ using Fisher's exact test; SOEP risk question: $\mathrm{p}=$ 0.353; Cognitive Reflection test: $\mathrm{p}=0.813$; Financial Literacy test: $\mathrm{p}=0.185$, all using Mann-Whitney tests. Money\&Appeal vs. AppealOnly: lottery task: $\mathrm{p}=0.562$ using Fisher's exact test; SOEP risk question: $\mathrm{p}=$ 0.524; Cognitive Reflection test: $\mathrm{p}=0.420$; Financial Literacy test: $\mathrm{p}=0.843$, all using Mann-Whitney tests.
} 
treatments, suggesting that the invitation emails do not have an impact on the composition of the subject pool.

Finally, as noted in Section 2.2., we can also use the lab experimental measures to indirectly test whether subjects sign up for pro-social reasons (i.e., whether $/ 3>0$ ). Assume for the moment that our Appeal treatments were not successful in increasing the pro-social motives, but that subjects do care about money (i.e., $b=0$ and $a>0$ ). Then, $/ 3>0$ would predict that subjects in AppealOnly are more pro-social compared to subjects in the two Money treatments (since the monetary payoff convinces also subjects with low pro-social motives to sign up), while $/ 3=0$ would predict no such difference. Since we find that none of our various measures of pro-social motives is significantly different between AppealOnly and either of the Money treatments, we conclude as before that $/ 3=0$, i.e., that pro-social motives play no big role when signing up for lab experiments. It has to be noted though that these tests are not very powerful since we have only few subjects in the AppealOnly treatment; we can, however, use a more powerful procedure. Given the assumption of $b=0$, the two Money treatments are identical as they only differ in the (non-effective) appeal. We can thus pool the data from these two treatments and compare them to AppealOnly, thereby increasing power. Reassuringly, these tests also show not significant differences across treatments, underlining our conclusion that $/ 3=0 .{ }^{18}$

\section{Conclusions}

In this paper we have studied the self-selection process of subjects into laboratory experiments. We sent differently-worded emails to first-year university students inviting them to sign up for the subject pool. In three treatments, we either mentioned the monetary payments that go along with participation in experiments; or appealed to subjects' willingness to help research; or both. We find that the sign-up rate drops by about two-thirds if we do not mention monetary rewards. Appealing to subjects' willingness to help research does not have a statistically discernible effect on sign-up. In a second step, we invited the sorecruited subjects to the lab to test whether they differ in their social values, cooperative ness, social approval need or sensitivity to experimenter demand. We do not find any significant differences across the three treatments.

"Comparisons of pooled Money treatments vs AppealOnly (using the same tests as for individual treatment comparisons mentioned above): social value orientation: $\mathrm{p}=0.579$, cooperativeness type in the public-goods game: $\mathrm{p}=0.807$, unconditional contribution in the public-goods game: $\mathrm{p}=0.373$, GSS trust question: $\mathrm{p}=0.098$, GCS score: $\mathrm{p}=0.118$, SDS score: $\mathrm{p}=0.828$, Tsutsui $\&$ Zizzo task: $\mathrm{p}=0.830$. 
We conclude that the main reason for students to self-select into becoming labexperimental subjects is to earn money. This is in line with the observation that many subjects repeatedly participate in lab experiments, often more than a dozen times, treating participation almost like a small side job. Given that money is the driver of selection, it is unlikely that the selection aspect of lab experiments leads to over-estimation of social preferences in the population from which participants are sampled. Of course, other factors could lead to distortions in the estimation of social preferences and affect the external validity of lab experiments, e.g., the fact that in a lab experiment participants are aware that they are being scrutinized (see Levitt and List, 2007, Falk and Heckman, 2009, and Camerer, 2011 for discussions).

Usual lab experimental subjects differ in two ways from the general population. We examined the self-selection process from the group of all students into the subject pool. We cannot say anything about the second margin of selection: students will differ from nonstudents by, for example, being younger, smarter, and by having a better socioeconomic background and higher lifetime earnings. Anderson et al. (2013) and Falk et al. (2013), among many others, study this margin of selection and usually find only small differences; if anything, students seem to be less pro-social than non-students. 


\section{References}

Anderson, J., S.V. Burks, J. Carpenter, L. Götte, K. Maurer, D. Nosenzo, R. Potter, K. Rocha, and A. Rustichini. 2013. Self-selection and variations in the laboratory measurement of other-regarding preferences across subject pools: Evidence from one college student and two adult samples. Experimental Economics 16(2), 170-189.

Banks, J., and Z. Oldfield. 2007. Understanding Pensions: Cognitive Function, Numerical Ability and Retirement Saving. Fiscal Studies 28(2), 143-170.

Bauman, Y., and E. Rose. 2011. Selection or indoctrination: Why do economics students donate less than the rest? Journal of Economic Behavior \& Organization 79(3), 318-327.

Belot, M., R. Duch, and L. Miller. 2010. Who should be called to the lab? A comprehensive comparison of students and non-students in classic experimental games. University of Oxford, Nuffield College Discussion Papers (2010-001).

Bénabou, R., and J. Tirole. 2003. Intrinsic and extrinsic motivation. Review of Economic Studies 70(3), 489-520.

Bohnet, I., and B.S. Frey. 1999. Social distance and other-regarding behavior in dictator games: Comment. American Economic Review 89(1), 335-339.

Brosig, J. 2002. Identifying cooperative behavior: Some experimental results in a prisoner's dilemma game. Journal of Economic Behavior \& Organization 47(3), 275-290.

Burks, S., J. Carpenter, and L. Götte. 2009. Performance pay and worker cooperation: Evidence from an artefactual field experiment. Journal of Economic Behavior \& Organization 70(3), 458-469.

Camerer, C. 2011. The Promise and Success of Lab-Field Generalizability in Experimental Economics: A Critical Reply to Levitt and List. SSRN Working Paper.

Charness, G., and U. Gneezy. 2008. What's in a name? Anonymity and social distance in dictator and ultimatum games. Journal of Economic Behavior \& Organization 68(1), 29-35.

Chen, Y., and S.X. Li. 2009. Group Identity and Social Preferences. American Economic Review 99(1), 431-457.

Cleave, B.L., N. Nikiforakis, and R. Slonim. 2013. Is There Selection Bias in Laboratory Experiments? The Case of Social and Risk Preferences. Experimental Economics 16(3), 372-382.

Coppock, A., and D.P. Green. 2013. Assessing the Correspondence between Experimental Results Obtained in the Lab and Field: A Review of Recent Social Science. Mimeo, Columbia University.

Cubitt, R.P., M. Drouvelis, S. Gächter, and R. Kabalin. 2011. Moral judgments in social dilemmas: How bad is free riding? Journal of Public Economics 95(3-4), 253-264. 
Dohmen, T.J., A. Falk, D. Huffman, U. Sunde, J. Schupp, and G.G. Wagner. 2011. Individual Risk Attitudes: Measurement, Determinants, and Behavioral Consequences. Journal of the European Economic Association 9(3), 522-550.

Eckel, C.C., and P.J. Grossman. 2000. Volunteers and Pseudo-Volunteers: The Effect of Recruitment Method in Dictator Experiments. Experimental Economics 3(2), 107-120.

Falk, A., and J.J. Heckman. 2009. Lab Experiments Are a Major Source of Knowledge in the Social Sciences. Science 326(5952), 535-538.

Falk, A., S. Meier, and C. Zehnder. 2013. Do Lab Experiments Misrepresent Social Preferences? The case of self-selected student samples. Journal of the European Economic Association 11(4), 839-852.

Fischbacher, U. 2007. z-Tree: Zurich toolbox for ready-made economic experiments. Experimental Economics 10(2), 171-178.

Fischbacher, U., S. Gächter, and E. Fehr. 2001. Are people conditionally cooperative? Evidence from a public goods experiment. Economics Letters 71(3), 397-404.

Frank, B. 1998. Good news for experimenters: subjects do not care about your welfare. Economics Letters 61(2), 171-174.

Frank, R.H., T. Gilovich, and D.T. Regan. 1993. Does studying economics inhibit cooperation? Journal of Economic Perspectives 7(2), 159-171.

Frederick, S. 2005. Cognitive Reflection and Decision Making. Journal of Economic Perspectives 19(4), 25-42.

Frey, B.S., and S. Meier. 2003. Are political economists selfish and indoctrinated? Evidence from a natural experiment. Economic Inquiry 41(3), 448-462.

Gaudecker, H.-M. von, A. van Soest, and E. Wengström. 2012. Experts in experiments. Journal of Risk and Uncertainty 45(2), 159-190.

Glaeser, E.L., D.I. Laibson, J.A. Scheinkman, and C.L. Soutter. 2000. Measuring trust. Quarterly Journal of Economics 115(3), 811-846.

Greiner, B. 2004. An Online Recruitment System for Economic Experiments. In Forschung und wissenschaftliches Rechnen. GWDG Bericht 63, ed by. K. Kremer and V. Macho, 79-93. Göttingen: Ges. für Wiss. Datenverarbeitung.

Gudjonsson, G.H. 1989. Compliance in an interrogative situation: A new scale. Personality and Individual Differences 10(5), 535-540.

Guillén, P., and R.F. Veszteg. 2012. On "lab rats." The Journal of Socio-Economics 41(5), 714-720.

Harrison, G.W., M.I. Lau, and E. Elisabet Rutström. 2009. Risk attitudes, randomization to treatment, and self-selection into experiments. Journal of Economic Behavior \& Organization 70(3), 498-507. 
Heyman, J., and D. Ariely. 2004. Effort for Payment A Tale of Two Markets. Psychological Science 15(11), 787-793.

Hoffman, E., K. McCabe, and V.L. Smith. 1996. Social Distance and Other-Regarding Behavior in Dictator Games. American Economic Review 86(3), 653-60.

Jenni, K.E., and G. Loewenstein. 1997. Explaining the identifiable victim effect. Journal of Risk and Uncertainty 14(3), 235-257.

Kagel, J.H., R.C. Battalio, and J.M. Walker. 1979. Volunteer Artifacts in Experiments in Economics: Specification of the Problem and Some Initial Data from a Small-Scale Field Experiment. In Research in Experimental Economics, ed by. Vernon L. Smith, 1:169-197. Greenwich, CT: JAI Press.

Krawczyk, M. 2011. What brings your subjects to the lab? A field experiment. Experimental Economics 14(4), 482-489.

Levati, M.V., M. Ploner, and S. Traub. 2011. Are conditional cooperators willing to forgo efficiency gains? Evidence from a public goods experiment. New Zealand Economic Papers 45(1), 47-57.

Levitt, S.D., and J.A. List. 2007. What do laboratory experiments measuring social preferences reveal about the real world? Journal of Economic Perspectives 21(2), 153-174.

Liebrand, W.B.G. 1984. The effect of social motives, communication and group size on behaviour in an N-person multi-stage mixed-motive game. European Journal of Social Psychology 14(3), 239-264.

List, J.A. 2007. Field Experiments: A Bridge between Lab and Naturally Occurring Data. The B.E. Journal of Economic Analysis \& Policy 6(2).

Marwell, G., and R.E. Ames. 1981. Economists free ride, does anyone else? Experiments on the provision of public goods, IV. Journal of Public Economics 15(3), 295-310.

Offerman, T., J. Sonnemans, and A. Schram. 1996. Value Orientations, Expectations and Voluntary Contributions in Public Goods. Economic Journal 106, 817-845.

Park, E.-S. 2000. Warm-glow versus cold-prickle: a further experimental study of framing effects on free-riding. Journal of Economic Behavior and Organization 43, 405-421.

Rosenthal, R., and R.L. Rosnow. 1969. The Volunteer Subject. In Artifact in Behavioral Research, ed by. Robert Rosenthal and Ralph L. Rosnow, 61-118. New York and London: Academic Press.

Rosenthal, R., and R.L. Rosnow. 1975. The Volunteer Subject. Wiley Series of Personality Processes. New York: Wiley.

Rustagi, D., S. Engel, and M. Kosfeld. 2010. Conditional Cooperation and Costly Monitoring Explain Success in Forest Commons Management. Science 330(6006), 961-65.

Slonim, R., C. Wang, E. Garbarino, and D. Merrett. 2013. Opting-In: Participation Biases in the Lab. Journal of Economic Behavior \& Organization 90, 43-70. 
Small, D.A., and G. Loewenstein. 2003. Helping a victim or helping the victim: Altruism and identifiability. Journal of Risk and Uncertainty 26(1), 5-16.

Stöber, J. 2001. The Social Desirability Scale-17 (SDS-17): Convergent Validity, Discriminant Validity, and Relationship with Age. European Journal of Psychological Assessment 17(3), 222-232.

Stoop, J., C.N. Noussair, and D. van Soest. 2012. From the lab to the field: Cooperation among fishermen. Journal of Political Economy 120(6), 1027-1056.

Tishler, C.L., and S. Bartholomae. 2002. The recruitment of normal healthy volunteers: a review of the literature on the use of financial incentives. Journal of Clinical Pharmacology 42(4), 365-375.

Tomporowski, P.D., R.G. Simpson, and L. Hager. 1993. Method of recruiting subjects and performance on cognitive tests. The American journal of psychology 106(4), 499-521.

Tsutsui, K., and D.J. Zizzo. forthcoming. Group Status, Minorities and Trust. Experimental Economics

Zizzo, D.J. 2010. Experimenter demand effects in economic experiments. Experimental Economics 13(1), 75-98. 


\section{Online Appendix A - Recruitment Messages}

Money\&Appeal recruitment message. The sentences deleted in the MoneyOnly treatment message are underlined and within square brackets. The sentences deleted in the AppealOnly treatment message are in italics and within parentheses.

\section{Dear \#name\#,}

We are a group of researchers based at the School of Economics, and we would like to invite you to participate in our studies. [Participation is fun and your collaboration will be of immense value to our scientific investigations.] (You will typically receive some reward (usually cash) in return for your participation.) To participate in our studies you need to register with us at: http://www.nottingham.ac.uk/economics/cedex/register/

Once you register you will be eligible to receive invitations for individual studies. The invitations will tell you the dates and times and any other necessary information. Note that registering with us does not commit you to anything. You are always free to accept or ignore a particular invitation. You can also deregister at any time.

[Our research investigates how people make decisions and for that we require the participation of volunteers: your participation is crucial to the success of our research, and we will highly appreciate your contribution and be really grateful for your collaboration.] If you have never taken part in our studies the best way to describe them is as a game in which you will act as a trader or other type of decision maker. Any interaction with other participants is typically via a computer network. There is no chance of your losing anything - at worst you will win nothing - and no special skills are required. Participating in a study usually does not take longer than an hour and normally takes place at the School of Economics (invitations for individual studies will give you more precise details about duration and location). (We pay you when you take part in our studies. We do not wish to create expectations about the payments, but we can tell you that most participants in previous experiments have been pleased with their cash rewards.) Your participation is strictly confidential: we never reveal your identity to other participants or anyone else.

We have been conducting these studies for nine years now. We had several thousands of students take part in many studies over the years. If you register, your registration will remain valid, and you will remain eligible to receive invitations, until the end of your studies (unless you choose to deregister in the meantime). Once again, if you wish to register, you can do it at: http://www.nottingham.ac.uk/economics/cedex/register/ 


\section{Online Appendix B - Lab Experiment Invitation Letter \& Instructions}

\section{Lab experiment invitation email}

Dear \#fname\# \#lname\#,

You are registered with CeDEx to participate in experiments. We would like to invite you to take part in our upcoming experiment. The experiment will take place in the CeDEx computer lab, room C41, Sir Clive Granger Building. We are planning the following sessions (you can participate in one session only):

\section{\#sessionlist\#}

If you would like to participate, please click on the link below to sign up to the session of your choice. Please note: people that sign up to a session and do not turn up cause us problems; sign up to a session only if you are sure you can attend it, and if you sign up please do attend. We operate a policy of removing participants from our database who sign up but then fail to turn up (without good reason).

\section{\#link\#}

(If the link does not work, copy it and paste it into the address field of your internet browser.) Please be on time and remember to bring your Student ID to the session.

This experiment is named JADN. Please include "JADN" in the subject field of any email you send CeDEx regarding this experiment.

Best regards, Johannes Abeler and Daniele Nosenzo

\section{Lab experiment instructions}

\section{PRELIMINARY INSTRUCTIONS}

Welcome! You are about to take part in a decision-making experiment. This experiment is run by the "Centre for Decision Research and Experimental Economics" and has been financed by various research foundations.

There are other people in this room, who are also participating in this experiment. All participants are reading the same instructions and have been recruited in the same way. Likewise, everyone is participating in this experiment for the first time. It is important that you do not talk to any of the other participants during the experiment. If you have a question at any time, raise your hand and a monitor will come to your desk to answer it.

This experiment consists of six different parts.

In each part you will be asked to make one or more decisions. Decisions made in one part of the experiment will bear no consequences for the other parts of the experiment. 
During the experiment you will have a chance to earn money. The total amount you will earn from the experiment will be the sum of the earnings you make in the different parts of the experiment. During the experiment your earnings will be calculated in points. These point earnings will be converted into cash at a rate of $10 \mathrm{p}$ per point. In addition to the money you will earn during the experiment, we will pay you $£ 1.50$ for showing up today. Your cash earnings will be paid to you in private at the end of the experiment.

You will be informed of any outcome (including your earnings) from the six parts of the experiment only at the end of the session. Therefore, in any given part of the experiment everyone will make their decisions without knowing any outcome from the previous parts.

You find on your desk instructions for PART 1 of the experiment. You will receive instructions for the other parts of the experiment gradually, as the experiment progresses.

If you have a question now, please raise your hand and a monitor will come to your desk.

\section{PART 1}

At the beginning of PART 1 the computer will randomly pair you with another person in this room. You will remain paired with this person for the whole duration of PART 1. At the end of PART 1 the pair will be dissolved, and you will not be matched with this other person again during today's experiment. You will not learn the identity of the person you are paired with in PART 1, neither during, nor after, today's session.

In PART 1 of the experiment you and the person you are paired with will be asked to make choices in a series of 24 situations. You and the other person will make choices independently and will not learn each other choices at any point during the experiment.

For each situation you will have to choose between two options: Option A or Option B. Each option specifies a number of points that you will receive or pay ("Points for you"), and a number of points that the other person will receive or pay ("Points for other").

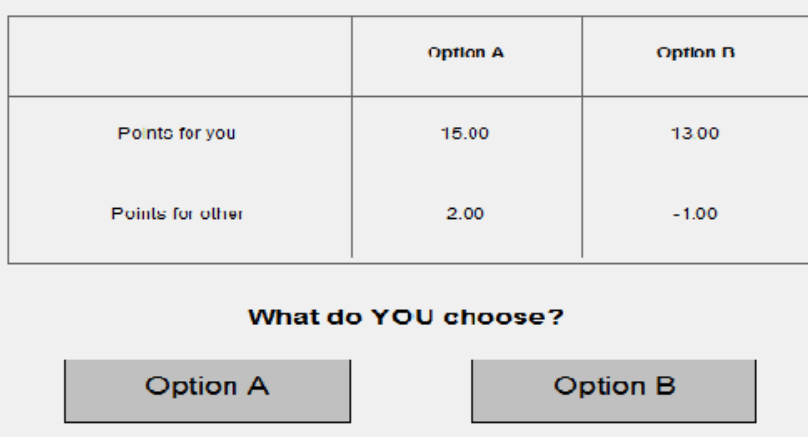

For example, a possible situation may look as follows:

In this example situation, if you choose Option A you receive 15 points and the other person receives 2 points. If you choose Option $\mathrm{B}$, you receive 13 points and the other person has to pay 1 point. Likewise, if the person you are paired with faces this situation and chooses Option A, he or she receives 15 points and you receive 2 points. If the person you are paired with chooses Option $\mathrm{B}$, he or she receives 13 points and you have to pay 1 point. 
Thus, in each situation your earnings depend on the number of points that you assign to yourself, and on the number of points that the other person assigns to you. For example, suppose that in the example situation above you choose Option A and the other person chooses Option B. Your total earnings for the situation will be 14 points: 15 points that you assign to yourself minus 1 point that the other person makes you pay. The earnings of the other person will be equal to 15 points: 13 points that he or she assigns to him or herself plus 2 points that you assign to him or her.

Your total earnings from PART 1 of the experiment will be the sum of the earnings you make in the 24 situations. You will learn your earnings from PART 1 at the end of today's session. You will be paid in private and in cash at the end of the experiment.

Please raise your hand if you have any questions.

To make sure everyone understands the instructions, please complete the questions about PART 1 below. In a couple of minutes someone will come to your desk to check the answers. (The decisions and earnings used for the questions below are simply for illustrative purposes. In the experiment the decisions and earnings will depend on the actual choices of the participants.).

Questions about PART 1:

1. How many choices will you make in total in PART 1 ?

2. Suppose that in the example situation above you choose Option B and the person you are paired with also chooses Option B. How much would you earn? How much would the other person earn?

3. Is the following statement true: you will not learn the choices made by the other person, nor will he or she learn your choices during today's experiment

4. Is the following statement true: your total earnings from PART 1 will be determined by adding the earnings you make in each of the 24 situations

\section{PART 2}

At the beginning of PART 2 the computer will randomly match you with three other participants in this room to form a group of four people. You will remain in this group for the whole duration of PART 2. At the end of PART 2 the group will be dissolved, and you will not be matched with these three participants again during this experiment. You will not learn the identity of these participants neither during, nor after today's session.

\section{The Basic Decision Situation}

The basic decision situation is simple. Each group member is given an endowment of 20 points, and has to decide how many of these points to place into a private account and how many to contribute to a group project.

Each point a group member places into his or her private account earns 1 point to that person. For example, if you place 20 points into your private account (and therefore do not contribute to the group project) your earnings from your private account will be 20 points. If you place 6 points into your private account, your earnings from your private account will be 6 points. No one except you earns points from your private account. 
Each point contributed to the group project generates 1.6 points to be shared equally among the group members. For example, if the sum of all contributions to the project in your group is 60 points, then the project generates $60 \times 1.6=96$ points. These will be shared equally among you and the three other members of your group, so each of you will receive $96 \pm 4=24$ points. As another example, if you and the three other group members contribute a total of 10 points to the project, each of you will receive: $(10 \times 1.6) \pm 4=4$ points.

Your total earnings from the decision situation are given by the sum of your earnings from your private account and your earnings from the group project.

To make sure everyone understands the instructions so far, please complete the questions on the next page. If you want to, you can use an electronic calculator while you answer the questions. To use the electronic calculator, click the CALCULATOR icon on the bottom-right corner of your computer screen. In a couple of minutes someone will come to your desk to check your answers. (The decisions and earnings used for the questions below are simply for illustrative purposes. In the experiment decisions and earnings will depend on the actual choices of the participants.).

\section{Questions about PART 2:}

1. Each group member has 20 points. Assume that none of the four group members (including you) contributes anything to the project.

What are your total earnings?

What are the earnings of each other member of your group?

2. Each group member has 20 points. You contribute 20 points to the project. Each of the three other members of your group also contributes 20 points to the project.

What are your total earnings?

What are the earnings of each other member of your group?

3. Each group member has 20 points. Suppose that the other three members of your group contribute a total of 30 points to the project.

a. What are your total earnings if - in addition to these 30 points - you contribute 0 points to the group project?

b. What are your total earnings if - in addition to these 30 points - you contribute 15 points to the group project?

4. Each group member has 20 points. Suppose that you contribute 8 points to the project.

a. What are your total earnings if - in addition to your 8 points - the other group members contribute a total of 7 points to the group project?

b. What are your total earnings if - in addition to your 8 points - the other group members contribute a total of 22 points to the group project?

\section{How You Make Decisions}


PART 2 of the experiment is based on the decision situation just described above. As you know you will have an endowment of 20 points. You will have to decide how many of these points to contribute to the group project. Any point that you do not contribute to the project will be automatically placed into your private account.

In this experiment we ask you to make two types of decisions. We will refer to these two decision types as "the unconditional contribution decision" and "the contribution table". You will make these decisions on the computer by completing two screens. Note that you will complete these screens only once, there is no repetition.

On the first screen, you have to make your unconditional contribution decision by typing in the number of points (between 0 and 20) you contribute to the group project. This is how the screen where you indicate your unconditional contribution will look like:

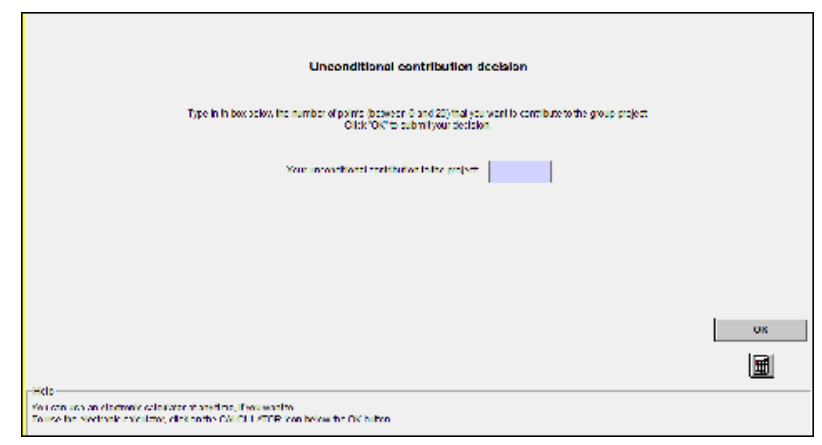

On the second screen, you have to fill out a contribution table where you indicate how many points you contribute to the project for each possible average contribution of the other group members (rounded to the closest whole number). Thus, with the contribution table you can condition your contribution decision on what the other group members contribute on

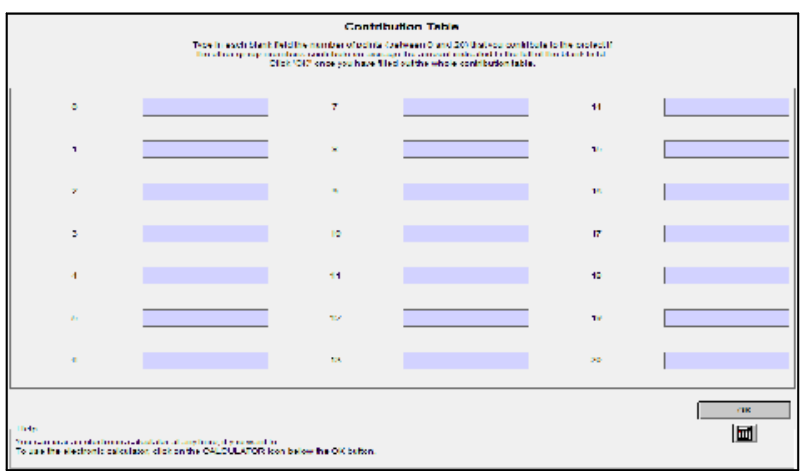

average. This is how the screen containing the contribution table will look like:

The numbers displayed to the left of each blank field are the possible (rounded) average contributions of the three other group members. We want to know how many points you contribute to the project for any possible average contribution of the other group members. Thus, you have to make a contribution decision for every possible average contribution of the other group members. In each blank field you must indicate the number of points (between 0 and 20) that you contribute to the project if the other group members contribute on average the amount indicated to the left of the blank field.

\section{How Your Earnings Are Determined}

In PART 2 of the experiment we ask you to make an unconditional contribution decision and to fill out a contribution table. However, only one type of decision will be used for determining your earnings in PART 2. Which type of decision will be used to compute 
earnings will be determined at random after you have made both types of decisions. Thus, at the time you make these decisions you do not know which one will be relevant for the computation of earnings. Therefore, you will have to think carefully about both types of decisions because both can become relevant for you.

After all group members have made their decisions, the computer will randomly select one group member. For the selected group member the contribution table will be used for the computation of earnings. For the other three group members who are not selected the unconditional contribution decision will be used. Thus,

If you are selected at random by the computer: then, we will compute earnings using your contribution table and the three unconditional contribution decisions of the other members of your group. We will average the unconditional contributions of the three other members of your group and round it to the closest whole number. We will then look at your contribution table to find out the number of points that you decided to contribute when the other group members make that average contribution.

If you are not selected at random by the computer: then, we will compute earnings using your unconditional contribution decision, the unconditional contribution decisions of the two other members of your group who have not been selected, and the contribution table of the member of your group who has been selected. We will compute the average of your unconditional contribution and the unconditional contributions of the two other non-selected members of your group, and round it to the closest whole number. We will then look at the contribution table of the selected group member to find out the number of points that he or she contributes when the other group members make that average contribution.

You will learn your earnings from PART 2 at end of today's session. You will be paid in private and in cash at the end of the experiment.

Please raise your hand if you have any questions.

As before, to make sure everyone understands the instructions about PART 2, please complete the questions below. In a couple of minutes someone will come to your desk to check your answers. (The decisions and earnings used for the questions below are simply for illustrative purposes. In the experiment decisions and earnings will depend on the actual choices of the participants.).

\section{Questions about PART 2:}

1. How many types of decisions will you make in PART 2?

2. How many times will you make each type of decision?

3. Is the following statement true: in the contribution table you have to enter 21 contribution decisions, one for each possible (rounded) average contribution of the other group members.

4. Suppose that you are selected at random by the computer - so earnings are computed using your contribution table and the three unconditional contribution decisions of the other group members. Suppose that the three other members of your group contribute 0,2 and 4 points. Their average contribution is therefore 2 points. Suppose that you decided to contribute 2 points when the other group members contribute on average 2 points. What are your total earnings? 


\section{PART 3 to PART 6}

For the remaining four parts of the experiment you will not be matched with any of the other participants in this room. Thus, the decision situations in the next four parts of the experiment will not involve any interaction with the other participants in today's experiment, and your earnings will be independent from their decisions.

You will receive the instructions for each of the four remaining parts of the experiment directly on your computer screen. Shortly, you will be shown instructions for PART 3. Once everyone in the room has completed PART 3, you will be shown the instructions for PART 4 , and so on.

The instructions for each part of the experiment will explain whether and how you can earn points in that part. So, it is important that you read the instructions carefully.

If you have a question at any time during the rest of the experiment, raise your hand and a monitor will come to your desk to answer it.

Please raise your hand if you have any questions now. 


\begin{tabular}{|lll|}
\hline & Option A & Option B \\
1. & 0,15 & $3.9,14.5$ \\
2. & $3.9,14.5$ & $7.5,13$ \\
3. & $7.5,13$ & $10.6,10.6$ \\
4. & $10.6,10.6$ & $13,7.5$ \\
5. & $13,7.5$ & $14.5,3.9$ \\
6. & $14.5,3.9$ & 15,0 \\
7. & 15,0 & $14.5,-3.9$ \\
8. & $14.5,-3.9$ & $13,-7.5$ \\
9. & $13,-7.5$ & $10.6,-10.6$ \\
10. & $10.6,-10.6$ & $7.5,-13$ \\
11. & $7.5,-13$ & $3.9,-14.5$ \\
12. & $3.9,-14.5$ & $0,-15$ \\
13. & $0,-15$ & $-3.9,-14.5$ \\
14. & $-3.9,-14.5$ & $-7.5,-13$ \\
15. & $-7.5,-13$ & $-10.6,-10.6$ \\
16. & $-10.6,-10.6$ & $-13,-7.5$ \\
17. & $-13,-7.5$ & $-14.5,-3.9$ \\
18. & $-14.5,-3.9$ & $-15,0$ \\
19. & $-15,0$ & $-14.5,3.9$ \\
20. & $-14.5,3.9$ & $-13,7.5$ \\
21. & $-13,7.5$ & $-10.6,10.6$ \\
22. & $-10.6,10.6$ & $-7.5,13$ \\
23. & $-7.5,13$ & $-3.9,14.5$ \\
24. & $-3.9,14.5$ & 0,15 \\
(The first number is own & \\
\hline
\end{tabular}




\section{Online Appendix D -SDS-17 and GCS items}

\section{SDS-17 items}

1. I sometimes drop litter rather than carry it to a bin.

2. I always admit my mistakes openly and face the potential negative consequences.

3. In traffic I am always polite and considerate of others.

4. I always accept others' opinions, even when they don't agree with my own.

5. I take out my bad moods on others now and then.

6. There has been an occasion when I took advantage of someone else.

7. In conversations I always listen attentively and let others finish their sentences.

8. I never hesitate to help someone in case of emergency.

9. When I have made a promise, I keep it - no ifs, ands or buts.

10. I occasionally speak badly of others behind their back.

11. I would never live off other people.

12. I always stay friendly and courteous with other people, even when I am stressed out.

13. During arguments I always stay objective and matter-of-fact.

14. There has been at least one occasion when I failed to return an item that I borrowed.

15. I always eat a healthy diet.

16. Sometimes I only help because I expect something in return.

\section{GCS items}


1. As a child, I always did as my parents told me.

2. I give in easily when I am pressured.

3. I am not too concerned what people think of me.

4. I tend to become easily alarmed and frightened when in the company of people in authority.

5. When I was a child I sometimes took the blame for things I had not done.

6. When I am uncertain about things I tend to accept what people tell me.

7. I tend to go along with what people tell me even when I know that they are wrong.

8. I would describe myself as a very obedient person.

9. I would never go along with what people tell me in order to please them.

10. I find it very difficult to tell people when I disagree with them.

11. I tend to give in to people who insist that they are right.

12. I try very hard not to offend people in authority.

13. I strongly resist being pressured to do things I don't want to.

14. I generally tend to avoid confrontation with people.

15. I try to please others.

16. People in authority make me feel uncomfortable and uneasy.

17. I try hard to do what is expected of me.

18. Disagreeing with people often takes more time than it is worth.

19. I generally believe in doing as I am told.

20. I believe in avoiding rather than facing demanding situations. 


\section{Online Appendix E - CRT and Financial Literacy test questions}

CRT Q.1 - A bat and a ball cost $£ 1.10$ in total. The bat costs $£ 1.00$ more than the ball. How much does the ball cost (in pence)?

$C R T Q .2$ - If it takes 5 machines 5 minutes to make 5 widgets, how long would it take 100 machines to make 100 widgets (in minutes)?

CRT Q.3 - In a lake, there is a patch of lily pads. Every day, the patch doubles in size. If it takes 48 days for the patch to cover the entire lake, how long would it take for the patch to cover half of the lake (in days)?

Financial Literacy Q.1- In a sale, a shop is selling all items at half price. Before the sale, a sofa costs $£ 300$. How much will it cost in the sale?

Financial Literacy $Q .2$ - If the chance of getting a disease is 10 per cent, how many people out of 1,000 would be expected to get the disease?

Financial Literacy Q.3 - A second hand car dealer is selling a car for $£ 6,000$. This is two-thirds of what it cost new. How much did the car cost new?

Financial Literacy Q.4 - If 5 people all have the winning numbers in the lottery and the prize is $£ 2$ million, how much will each of them get?

Financial Literacy Q.5 - Let's say you have $£ 200$ in a savings account. The account earns ten per cent interest per year. How much will you have in the account at the end of two years? 